\title{
REVIEW
}

\section{Mechanisms of ligand specificity of the mineralocorticoid receptor}

\author{
Peter J Fuller, Yizou Yao, Jun Yang and Morag J Young \\ Prince Henry's Institute and the Monash University, Department of Medicine, PO Box 5152, Clayton, Victoria 3168, Australia \\ (Correspondence should be addressed to P J Fuller; Email: peter.fuller@princehenrys.org)
}

\begin{abstract}
The mineralocorticoid receptor (MR) differs from the other steroid receptors in that it responds to two physiological ligands, aldosterone and cortisol. In epithelial tissues, aldosterone selectivity is determined by the activity of $11 \beta$-hydroxysteroid dehydrogenase type 2 , while in other tissues, including the heart and regions of the central nervous system, cortisol is the primary ligand for the MR where it may act as an antagonist. Clinical trials have demonstrated the potential of MR antagonists in the treatment of cardiovascular disease, though their use has been limited by concurrent hyperkalaemia. In order to better target the MR, an understanding of the structural determinants of tissue- and ligand-specific MR activation is needed. Interactions of the MR have been identified, which exhibit ligand discrimination and/or specificity. These interactions include those of the ligand-binding
\end{abstract}

domain with ligand, with the $\mathrm{N}$-terminal domain and with putative co-regulatory molecules. Agonist and antagonist binding have been characterised using chimeras between the human MR and the glucocorticoid receptor or the zebra fish MR together with molecular modelling. The interaction between the $\mathrm{N}$-terminus and the C-terminus is aldosterone dependent but is unexpectedly antagonised by cortisol and deoxycorticosterone in the human MR. Nuclear receptormediated transactivation is critically dependent on, and modulated by, co-regulatory molecules. Proteins that interact with the MR in the presence of either aldosterone or cortisol, but not both, have been identified. The successful identification of ligand-specific interactions of the MR may provide the basis for the development of novel MR ligands with tissue specificity. Journal of Endocrinology (2012) 213, 15-24

\section{Introduction}

The mineralocorticoid receptor (MR) is arguably unique amongst the nuclear receptors in that it has two physiological ligands, aldosterone and cortisol (corticosterone in rodents). There is increasing evidence that the consequences of this binding to the $\mathrm{MR}$ are not equivalent for these ligands. Previous discussion of specificity at the MR (Fuller et al. 2000, Farman \& Rafestin-Oblin 2001) has tended to focus on specificity between the MR and the closely related glucocorticoid receptor (GR), both of which can be activated by physiological glucocorticoids. In the intervening decade, there have been a number of studies that have not only highlighted the differences between aldosterone and cortisol, acting at the MR, but also identified mechanisms by which this specificity may be conferred. This review seeks to highlight the molecular mechanisms that may contribute to differential activation of the MR by cortisol and aldosterone (Fig. 1) and explores the structural basis of these differences. This question is much more than an exercise in molecular dissection in that discrimination of ligand-mediated effects is the basis for a number of current and emerging therapies directed at other members of the steroid receptor subfamily of the nuclear receptor superfamily. In the case of the MR, clinical trials have demonstrated the value of MR antagonists in the treatment of cardiac failure, but their use has been limited by concurrent hyperkalaemia. Understanding relevant mechanisms at the MR opens the possibility of novel therapeutic approaches, particularly in the area of cardiovascular disease.

\section{Pre-receptor mechanisms}

The concept that access of ligands to their receptors may be regulated through pre-receptor mechanisms, including both activation and inactivation of the ligand, is well established in endocrinology. In the case of the MR, the work of both Edwards et al. (1988) and Funder et al. (1988) over 20 years ago clearly established that in epithelial tissues, access of aldosterone and a lack of access of cortisol to the MR were determined by the enzyme 11 $\beta$-hydroxysteroid dehydrogenase type 2 (11 $\beta-H S D 2)$. These landmark studies resolved a longstanding conundrum in the field that the MR bound 


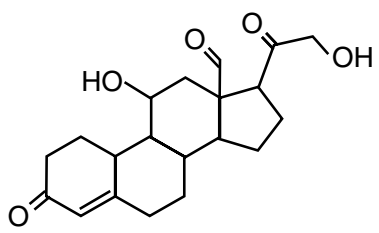

Aldosterone

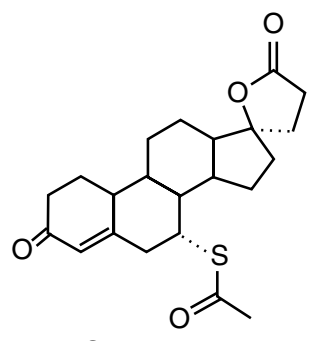

Spironolactone
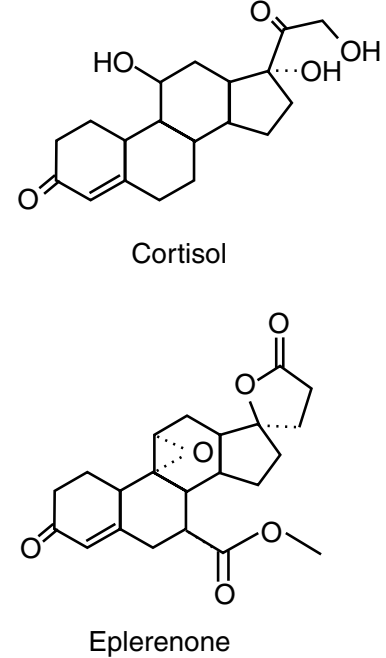

Eplerenone
Figure 1 Structures: chemical structures of the mineralocorticoid receptor agonists, aldosterone and cortisol and the antagonists, spironolactone and eplerenone.

cortisol with an affinity close to that of aldosterone, yet cortisol circulates at concentrations that are orders of magnitude higher than that of aldosterone. Even allowing for issues of plasma binding, the MR would, with normal cortisol levels, be permanently occupied by cortisol except perhaps at the nadir of the diurnal cycle. Subsequent studies have shown the intimate association in sodium-transporting epithelial tissues of $11 \beta-H S D 2$ with the MR (Odermatt et al. 2001). 11 $\beta$-HSD2 metabolises cortisol to cortisone (or corticosterone to 11-deoxycorticosterone in rodents), cortisone being unable to bind or activate the MR. Both the physiology and the pathophysiology of $11 \beta-$ HSD2 have been extensively reviewed (see for instance Odermatt \& Atanasov (2008)) and will not be further addressed in this review.

\section{Non-epithelial tissues}

In the initial characterisation of receptors for the corticosteroids, the existence of two distinct receptors was clearly identified, and these were originally termed type 1 and type 2 receptors (Feldman et al. 1973). Subsequently, the type 1 receptor was identified as being the primary target for the mineralocorticoid hormone aldosterone and hence is now called the MR. To some extent, this nomenclature is unfortunate in the sense that although the role of aldosterone is arguable as implied by the term 'mineralocorticoid', i.e. the regulation of vectorial electrolyte transport, the role of the $\mathrm{MR}$ is much broader. The MR is widely distributed in a range of tissues, not only epithelial but also non-epithelial tissues (Fuller \& Young 2005, Viengchareun et al. 2007). The function of the MR in many of these tissues remains to be determined. In some epithelial tissues such as lung and breast, it is not clear that its role relates specifically to electrolyte transport. In other tissues such as adipose tissue, where the receptor appears to play a fundamental role in adipocyte differentiation (Caprio et al. 2007), there is no suggestion that sodium transport is relevant. In the cardiovascular system, the $\mathrm{MR}$ is expressed not only in the cardiomyocytes but also in the endothelium and smooth muscle cells of the vasculature. In the vasculature, there is a co-expression of $11 \beta-\mathrm{HSD} 2$ but not in the cardiomyocyte (Fuller \& Young 2005).

Similarly, the MR is expressed extensively in the central nervous system (CNS), and indeed, the hippocampus arguably has the highest abundance of MR of any tissue in the body with the possible exception of the distal colon (Fuller \& Verity 1990). The function of the MR in the CNS has been the subject of extensive investigation (for a review, see Joëls et al. (2007)); it appears to have fundamental roles in diverse behavioural responses including memory and affect. In only a small number of nuclei in the CNS, there is co-expression of $11 \beta-H S D 2$ and the MR; in these nuclei, there is compelling evidence that the role does relate to sodium balance, in this case, the regulation of salt appetite (Geerling \& Loewy 2009).

Our recent studies (Rickard et al. 2009) and subsequent studies from other groups (Usher et al. 2010) have established a very fundamental role for the $\mathrm{MR}$ in the regulation of the cells of the monocyte/macrophage lineage. These cells have previously been well characterised with respect to their response to synthetic glucocorticoids acting via the GR, which predominantly serve to mediate an anti-inflammatory response (Rickard \& Young 2009). Hoppmann et al. (2010) have recently reported similar findings for inflammatory adipocyte responses. The current evidence would therefore suggest that the activation of the $\mathrm{MR}$ in a range of tissues mediates a pro-inflammatory response, and thus, we see in this context an interesting 'yin and yang' with respect to the MR and GR.

Perhaps fundamental to interpreting the significance of this situation are the dose-response curves, with the MR responding to cortisol at much lower concentrations than the GR, a fact that is often overlooked. Indeed, in monocyte/macrophages perhaps more than any other, the postulate that the two receptors may expand the dynamic range of the response to cortisol, with the MR responding in the physiological range associated with a normal diurnal rhythm, and the GR responding to supraphysiological levels associated with stress and disease (Evans \& Arriza 1989), would seem to apply. Thus, a parsimonious interpretation is that the $\mathrm{MR}$ is involved in the initial activation of the response, and the GR serves to limit the extent of the response, and indeed perhaps turn off the response.

The MR is also expressed in the reproductive tract including the granulosa cells of the ovary (Fru et al. 2006). Here, there is evidence that the MR may play a role in the regulation of progesterone synthesis; in this context, it is curious that progesterone, which is itself an $\mathrm{MR}$ antagonist, is the parent molecule for the MR antagonists in clinical use, spironolactone and eplerenone. 


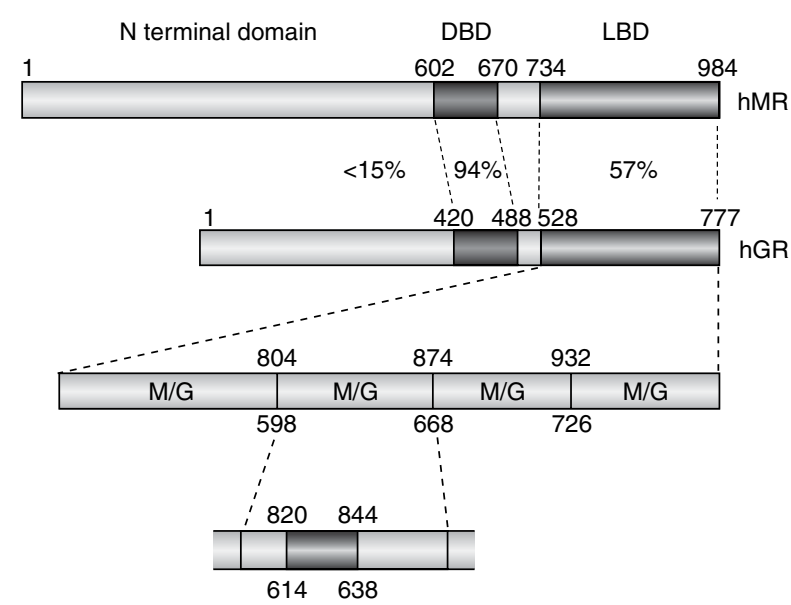

Figure 2 Schematic representation of the strategies used to create LBD chimeras between the hMR and the hGR. The structures of the $\mathrm{hMR}$ and hGR are shown with the $\mathrm{N}$-terminal, DNA-binding (DBD) and ligand-binding (LBD) domains. The amino acid numbers are shown above the receptors, and the homology is also shown as a percentage. The first set of chimeras where the LBD was broken into four regions resulted in 16 chimeras (Rogerson et al. 1999), and subsequently targeted chimeras of just the second region hMR (804-874)/hGR (598-668) were created (Rogerson et al. 2007). The 25 amino acids that conferred aldosterone-binding hMR (820-844) are shown at the bottom.

\section{MR: structural considerations}

The MR (Arriza et al. 1987), as with other members of the nuclear receptor superfamily, consists of three principal domains (Mangelsdorf et al. 1995, Gronemeyer et al. 2004; Fig. 2). A central cysteine-rich DNA-binding domain (DBD) defines the superfamily. Structural analysis has shown that the cysteine residues are coordinated by two zinc atoms creating the so-called zinc fingers, in reality $\alpha$-helices, one of which lies in the major groove of DNA where it makes nucleotidespecific contacts, the sequence of which defines the response element (Luisi et al. 1991). This region is highly conserved across the superfamily and consists of 66 or 68 amino acids. C-terminal to the DBD is a hinge region that is highly variable between receptors and links the DBD to the ligandbinding domain (LBD). This region is also highly conserved within the superfamily. In the case of the steroid receptors across the androgen receptor (AR), progesterone receptor (PR), GR and MRs, there is a $50-60 \%$ amino acid identity. The tertiary structure of the LBD is highly conserved across the superfamily and consists of $12 \alpha$-helices orientated in three anti-parallel layers with a ligand-binding pocket in the lower third of the molecule. The C-terminal helix, helix 12, in the presence of ligand forms a specific confirmation, which creates a groove into which co-activator molecules, with a leucine-rich LxxLL motif, bind. This function in the LBD is termed activation function $2(\mathrm{AF}-2)$ and it is ligand dependent. In the steroid receptors, including the MR (Bledsoe et al. 2005, Fagart et al. 2005, Li et al. 2005), helix 2 is unstructured, and so there are in fact only $11 \alpha$-helices, although the numbering observes the general convention for the family. The $\mathrm{N}$-terminal domain of the nuclear receptors is remarkably diverse with respect to both sequence and length. The N-terminal domain of the MR is the longest in the nuclear receptor (NR) superfamily, and it shares little homology with the other NRs, including the other steroid hormone receptors (Arriza et al. 1987). The N-terminal domain contributes to receptor-mediated transactivation through AF-1. The N-terminal domain is largely unstructured, and it has been shown to be an exemplar of a class of proteins whose function depends on this lack of structure (Fischer et al. 2010).

In effect, the structure of this region is defined by its other interacting protein, and thus, this flexibility provides a degree of promiscuity that enables a diversity of interactions.

\section{Aldosterone vs cortisol}

In classic mineralocorticoid target tissues such as the distal nephron or the distal colon, the response to activation of the MR by aldosterone or cortisol, in the absence of $11 \beta-H S D 2$ activity, appears equivalent (Fuller \& Young 2005). This appears not to be universally true in other tissues. Thus, for instance in the heart, we have presented evidence that corticosterone induces different, albeit overlapping patterns of gene expression (Wilson et al. 2009). Sato \& Funder (1996) reported that aldosterone-induced hypertrophy in neonatal myocytes was blocked by corticosterone. Similarly, Rossier et al. (2008) showed that the MR-mediated chronotropic response in cardiomyocytes was activated by aldosterone but not by corticosterone, except in the presence of an altered redox state. In a transgenic study in which $11 \beta-\mathrm{HSD} 2$ was overexpressed in cardiomyocytes, the authors argued that normal occupancy of the MR by corticosterone was neutral in contrast to the deleterious outcomes that were mediated by the inappropriate activation by aldosterone (Qin et al. 2003). In isolated rabbit cardiomyocytes, an antagonistic effect of cortisol on aldosterone activation of PKC signalling has been reported (Mihailidou \& Funder 2005). In the CNS, similar ligand discrimination has also been reported: Gomez-Sanchez et al. (1990) reported that the effects of i.c.v. infusion of aldosterone were blocked by both MR antagonists and corticosterone.

It has been argued that the differences seen between cortisol/corticosterone and aldosterone at the MR reflect the fact that despite having similar binding affinity constants, kinetic studies show a much faster off-rate for the glucocorticoids than for aldosterone, which in turn mediates a much stronger transcriptional response (Lombes et al. 1994, Hellal-Levy et al. 2000). That the interaction with the MR may be different for these ligands was demonstrated some years ago by Trapp \& Holsboer (1995) who showed that the aldosterone-bound MR was more resistant to proteolysis than either spironolactone- or cortisol-bound MR. 


\section{Binding to the MR LBD: aldosterone vs cortisol}

In order to understand the structural basis of the ability of the MR to bind both aldosterone and cortisol whilst the GR effectively binds only cortisol, our group exploited a chimeric approach (Rogerson et al. 1999). We and others (Benhamou et al. 1992, Keightley et al. 1998) had previously used this approach to determine the structural basis of differences in ligand binding across species. Rogerson et al. (1999) created 16 MR:GR LBD chimeras with the three break points chosen on the basis of sequence conservation to avoid disturbing secondary structure (Fig. 2). Although the strategy preceded the publication of the crystal structures of the GR (Bledsoe et al. 2002) and MR (Bledsoe et al. 2005, Fagart et al. 2005, Li et al. 2005) LBD, the structural integrity was retained in that all the chimeras were able to bind cortisol. When the second of the four segments of the LBD was derived from the MR (amino acids 804-874), aldosterone binding and transactivation was observed irrespective of the source of the first, third and fourth segments. This same region also conferred the ability of the chimeras to bind spironolactone (Rogerson et al. 2003) and eplerenone (Rogerson et al. 2004). These amino acids were the starting point for a series of smaller MR sequence substitutions in the GR LBD described in a subsequent study (Rogerson et al. 2007). Amino acids 820-844 of the human MR were found to be responsible for the binding specificity (Fig. 2) with at least four amino differences, MR vs GR, being responsible. Regions overlapping these 24 amino acids have been identified in other studies using AR:PR (Vivat et al. 1997) and GR:PR (Robin-Jagerschmidt et al. 2000) chimeras as well as a subsequent study using MR:GR chimeras (Martinez et al. 2005). Although all chimeras that bound aldosterone were also transactivated by aldosterone, this was not true for cortisol where binding occurred with all 16 chimeras, but transactivation was only observed when the chimera contained MR sequence at both the second and the fourth regions of the LBD or GR sequence (Rogerson et al. 1999, 2007). We interpret this observation as further evidence that the interactions between cortisol and the MR are not equivalent to those for aldosterone and the MR.

\section{Antagonists of the MR}

An extension of the distinction between ligands for the MR is the response to antagonists (Fig. 1). Bledsoe et al. (2005) have suggested that antagonism may occur through several different mechanisms. Competitive antagonism occurs where the LBD is largely unaltered but the necessary internal conformational changes fail to occur. Spironolactone is seen as fitting this 'passive' antagonism. Other categorisations include antagonism where an active conformational change occurs that precludes receptor dimerisation and DNA binding, and promotes degradation, and selective antagonists or agonists of transrepression, as has been described for the GR (de Bosscher et al. 2010). In addition to spironolactone, the other MR antagonist used in clinical practice is eplerenone, essentially a derivative of spironolactone, which is a derivative of progesterone. Although eplerenone has a lower affinity for the MR than spironolactone, it has greater specificity in that in contrast to spironolactone, it has a very low affinity for the other steroid receptors (Fagart et al. 2010). The distinction between antagonist and agonist in this context is subtle in that a single amino acid change at serine 810 in the human MR results in spironolactone and progesterone, both becoming agonist at the MR with significant clinical consequences (early onset hypertension that was catastrophically aggravated in pregnancy) in the kindred in which this mutation was identified (Geller et al. 2000, Zhang et al. 2005). Subsequently, it was shown that this Ser 810 Leu mutation also confers cortisone responsitivity on the MR (Rafestin-Oblin et al. 2003). Similarly, other studies have been able to manipulate the 'direction' of the response with point mutations in the LBD (Hultman et al. 2005, Li et al. 2005). Many studies have found that spironolactone alone has a weak ability to increase MR-mediated transcription, a response that can be enhanced by treatment with cyclic AMP analogues (Nordeen et al. 1995), or in a cell- and promoter-dependent context (Massaad et al. 1997).

The small difference between an agonist and an antagonist is further reinforced by the finding that in lower vertebrates, specifically the teleost fish, rainbow trout and zebra fish, the MR shows a similar pattern of response to both physiological mineralocorticoids and glucocorticoids to that observed for the mammalian MR, but in contrast, spironolactone and indeed progesterone show predominant agonist activity (Sturm et al. 2005, Pippal et al. 2011). The homology within the LBD of the human and zebra fish MR is $81 \%$, confirming that fairly subtle changes of amino acid sequence in the LBD can change the direction of the response. Indeed, the subtlety of the distinctions is such that eplerenone is predominantly an antagonist of aldosterone action at the zebra fish MR, as it is at the human MR (Pippal et al. 2011). The calcium channel antagonist, nimodipine, which shows antagonist activity at the human MR (Dietz et al. 2008), is also an antagonist at the zebra fish MR (Pippal et al. 2011). Dihydropyridine has been used as the basis for the development of non-steroidal MR antagonists (Dietz et al. 2008, Fagart et al. 2010).

\section{$\mathrm{N} / \mathrm{C}$ interaction}

Although the various domains of the nuclear receptors are often regarded as modular and somewhat independent, it is clear that specific interactions may occur between domains within the receptor. An interaction between the N-terminal domain and the LBD (N/C interaction) has been extensively characterised for the AR (Langley et al. 1995, He et al. 1999). Indeed, some patients with the androgen insensitivity syndrome have been shown to have mutations in the AR 
that quite specifically impair this interaction without impacting on other functions of the receptor (Thompson et al. 2001, Quigley et al. 2004). The significance of this interaction in the AR is further reinforced by the use of the interaction as a screen in the development of non-steroidal selective AR modulators (Miner et al. 2007). An N/C interaction has also been identified in other nuclear receptors, including the progesterone (Tetel et al. 1999) and oestrogen receptors (Métivier et al. 2002). This interaction is usually demonstrated using a mammalian-2 hybrid assay $(\mathrm{M}-2-\mathrm{H})$, which serves to identify protein-protein interactions (Fig. 3). One protein is linked to the GAL4 DBD and the other to an activation domain, often VP-16. These two components are independently transfected into cells, usually COS-1 cells, with the GAL4 promoter linked to a luciferase reporter gene. If there is a productive interaction between the two proteins of interest, then the activation domain will be brought into relationship with the GAL4 DBD bound to its promoter, and hence transcription will be initiated (Rogerson \& Fuller 2003). This assay has been used extensively in the characterisation of the N/C interaction in the AR. Some years ago, we reported an interaction between the MR LBD and the N-terminus (Rogerson \& Fuller 2003) using the M2-H assay under the same conditions as those used to demonstrate an interaction for the AR. Curiously, we were not able to demonstrate an interaction between the $\mathrm{N}$-terminus and the LBD of the GR. The MR N/C interaction was found to be ligand dependent, occurring in the presence of aldosterone. The analysis was, however, confounded to some extent by the strong transactivation activity in the AF-2 region of the MR LBD, which resulted in a significant level of activity in the absence of the $\mathrm{N}$-terminus VP-16 construct. If this activity was specifically eliminated through mutation of the glutamic acid at position 962 to alanine in the human MR (Fuse et al. 2000), the interaction was still observed (Rogerson \& Fuller 2003). Although this

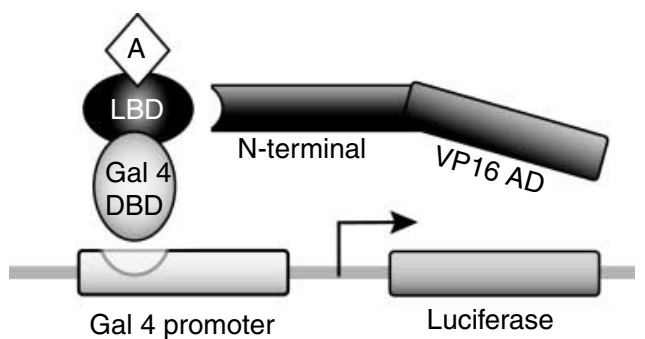

Figure 3 Schematic representation of the mammalian-2 hybrid assay used to demonstrate the N/C interaction. Cells in culture are transfected with three plasmids. The two expression plasmids encode a chimera of the GAL4 DBD with the MR LBD and a chimera of the MR N-terminal domain with the VP16 activation domain (VP16 AD). The reporter plasmid contains five GAL4 response elements in the promoter that regulates expression of the luciferase gene. Ligand, in this case aldosterone (A), is then added. The yeast-2-hybrid assay used to identify co-regulatory molecules follows a similar principle. mutation reduces the magnitude of interaction, it does not eliminate the interaction in contrast to what is seen with this mutation for interactions of the AF-2 region with coregulatory molecules (see below). Moreover, the interaction induced by aldosterone was antagonised by both spironolactone and eplerenone (Rogerson \& Fuller 2003); however, somewhat to our surprise, the aldosterone-mediated interaction was also antagonised by cortisol, which exhibited very low induction of the interaction. We were even more surprised to find that although the interaction was observed in the presence of the synthetic mineralocorticoid, $\alpha$-fludrocortisone, deoxycorticosterone was also a predominant antagonist of the interaction for the human MR (Pippal et al. 2009). Using a GST pulldown assay, we provided evidence that the interaction was a direct interaction between the N-terminus and the LBD (Pippal et al. 2009). This N/C interaction was observed in a range of cell lines, which is to say there was no evidence that cell-specific factors mediate the interaction. An important caveat with this observation is that this does not preclude the possibility that the consequences of the N/C interaction may exhibit cell specificity. The structural basis of the interaction remains unclear at this stage. The AR has specific motifs in the $\mathrm{N}$-terminal domain, FxxLF and WxxLF, which are known to mediate the interaction with the AF-2 region of the AR LBD (He et al. 2000). Such motifs do not exist in the MR N-terminus. Pascual-Le Tallec et al. (2003) have identified four sumoylation motifs in the $\mathrm{N}$-terminal domain; however, mutation of the lysine in each of these mutations to an arginine, which will preclude sumoylation, does not compromise the N/C interaction (Pippal et al. 2009). A series of truncation and internal deletion mutations of the $\mathrm{N}$-terminus have similarly failed to identify a specific region mediating the interaction, leading us to conclude that more than one region may be involved in mediating the interaction (Pippal et al. 2009). A key question with this interaction is whether it occurs within a given receptor molecule, i.e. is an intra-molecular interaction or an inter-molecular interaction between two receptors, perhaps bound, as is often the case, as dimers on the response element that is classically an inverted palindrome. Schaufele et al. (2005) have provided compelling evidence for an initial intra-molecular interaction in the unliganded AR but an inter-molecular interaction in the liganded AR when it has migrated to the nucleus. The notion that there might be more than one interacting domain in the N-terminus is consistent with multiple interactions across receptors to promote synergy in the interaction. It is perhaps of relevance that the regions of the MR N-terminal domain that contain the sumoylation motifs were initially identified as synergy motifs (Iñiguez-Lluhi \& Pearce 2000). Although it would appear that the AF-2 region makes some contribution to the $\mathrm{N} / \mathrm{C}$ interaction in that the strength of the interaction is diminished, albeit not eliminated, by mutation in the AF-2 region (Rogerson \& Fuller 2003), it would appear that residues elsewhere are also important. The same has been found for the AR where residues in helices 3, 4 and 12 have 
been identified as important in mediating the $\mathrm{N} / \mathrm{C}$ interaction (He et al. 2000, Estébanez-Perpiñá et al. 2005). Clearly, much work remains to be done in understanding both the nature and the significance of the N/C interaction observed in the MR. Although one can argue by analogy with the $\mathrm{AR}$ that the $\mathrm{N} / \mathrm{C}$ interaction is functionally significant, this remains to be formally demonstrated. One approach to addressing this question is to ask whether this interaction is conserved across evolution for the MR. Pippal et al. (2011) have recently reported that the $\mathrm{N} / \mathrm{C}$ interaction is also observed for the zebra fish MR. We were able to show that the interaction also occurs across species. Curiously, in contrast to the human MR, both deoxycorticosterone and cortisol were predominant agonists for the interaction, although spironolactone remains an antagonist. Although the significance of this latter observation is not clear, it does suggest that there are very subtle differences in sequence that profoundly alter the direction of the interaction. This again emphasises that subtle, but functionally significant, differences in the confirmation of the MR can be induced by different ligands.

\section{Post-translational modifications}

As with other steroid receptors, the $\mathrm{MR}$ is subject to a number of post-translational modifications including phosphorylation, sumoylation, ubiquitination and even acetylation (for reviews see Viengchareun et al. (2007) and Odermatt \& Atanasov (2008)). Kino et al. (2010) have recently identified a role for cyclin-dependent kinase 5-mediated phosphorylation in modulating MR transcriptional activity. Although one can speculate that the different conformations induced by aldosterone and cortisol might alter post-translational modifications, we are unaware of any direct evidence that this can occur.

\section{Co-activators}

The central role of co-regulatory molecules in mediating the genomic response to nuclear receptor activation is now well established, and indeed, over 350 co-regulatory molecules have been identified (Bulynko \& O'Malley 2011). In contrast to the other members of the nuclear receptor superfamily, including the steroid receptors, only a small number of co-regulatory molecules have been identified for the MR. These have been reviewed in some detail recently (Viengchareun et al. 2007, Yang \& Young 2009, Yang \& Fuller 2012). In addition to interacting with known wellcharacterised co-regulators such as the steroid receptor co-regulator 1 (SRC1), SRC2, SRC3 and PGC1 $\alpha$, a number of other MR co-regulators have been identified. Much of the work identifying MR-specific co-regulators has focused on identifying co-regulatory molecules that will discriminate between the MR and the GR. The strategy has primarily, but not exclusively, been to screen using the unique $\mathrm{N}$-terminal domain of the MR to identify receptor-specific interacting proteins (for recent reviews, see Yang \& Young (2009) and Yang \& Fuller (2012)). Conversely, if co-regulatory molecules are to be ligand discriminant, it arguably makes more sense that they would be interacting with the LBD rather than the N-terminus, although as is described below, this is not entirely true; indeed, the N/C interaction confirms that these domains are not truly independent. The classic interaction of a co-activator molecule with the LBD of the nuclear receptors involves an interaction between the AF-2 region of the LBD formed by helices 3, 4 and 12 interacting with an LxxLL motif in the co-regulatory molecule. The stability of this interaction is determined by a charge clamp between residues in helices 12 and 3 (Savkur \& Burris (2004)). In general, co-regulatory molecules have more than one of these motifs (Savkur \& Burris 2004, Li et al. 2005). Two studies sought to define the pattern of interaction by taking the LxxLL motifs from a series of known co-regulatory molecules and examining their interaction with the $M R$ in a mammalian-2 hybrid assay (Hultman et al. 2005) or an alpha screen ( $\mathrm{Li}$ et al. 2005). The first study examined 50 LxxLL motifs from 23 known co-regulators and the second, 38 motifs from 18 known co-regulators. What was remarkable about both of these studies was the relatively small number of these motifs that interacted with the MR. In addition, ligand discrimination was not observed unless mutations were inserted into the MR LBD (Li et al. 2005). We have recently addressed this question using a different approach (Yang et al. 2011). In this study, phage display was used to screen a library of random 19 amino acid peptides, half of which contained the LxxLL motif at their core. The library was screened with full-length MR, which identified a number of interactions, some of which occurred in the presence of aldosterone but not cortisol. Of particular interest was the finding that one of the random 19-mers was ligand discriminant in that it interacted with the full-length $M R$ in the presence of aldosterone but not cortisol. The physiological significance remains to be demonstrated. Of the published full-length co-regulatory molecules identified, which interact with the MR, only one has, to date, shown ligand specificity. Kitagawa et al. (2002) screened HeLa cell extracts using a region of the $\mathrm{N}$-terminus of the rat $\mathrm{MR}$ known to have transcriptional activity. They identified a complex containing RNA helicase A (RHA). When they explored the ability of the RHA-containing complex to mediate transactivation with the full-length receptor, transactivation was observed in the presence of aldosterone but not cortisol. It is tempting of course to speculate that this relates to the N/C interaction. The concept that the $\mathrm{N}$-terminal domain is important in defining the response has been reported previously: Jausons-Loffreda et al. (1994) demonstrated that the $\mathrm{N}$-terminal region was important if glucocorticoids were to mediate transactivation of the MR, whereas aldosterone was not dependent on this region. We have recently sought to identify ligand-dependent and ligand-discriminant 
interacting proteins for the MR using a yeast-2 hybrid screen (PJ Fuller, Y Yao and FM Rogerson 2009, unpublished observations; Fig. 3). Two commercially available yeast-2 hybrid libraries have been screened with the LBD of the MR in the presence of aldosterone or cortisol. A large number of interacting proteins were identified, including SRC1 and PGC1 $\alpha$, which are of course reassuring de facto-positive controls. A small number of interacting peptides were isolated from that screen whose interaction with the MR appeared to occur only in the presence of aldosterone but not cortisol, and, in the case of one clone, cortisol but not aldosterone. Some but not all of these fragments contained LxxLL motifs. The characterisation of these clones is the subject of ongoing work in the laboratory. The results of the yeast- 2 hybrid assay have been first validated in the mammalian-2 hybrid assay, and those in which the interaction is confirmed in the mammalian system have then been further analysed by the creation of full-length cDNAs for co-expression with the full-length human MR. At least two of these show clear aldosterone- but not cortisol-mediated transactivation in the presence of the full-length receptor, and the preliminary results of these analyses have been reported (Fuller et al. 2010). At this stage, the physiological significance of these observations remains to be clearly established. One can conclude from this analysis that, as previously shown by Kitagawa et al. (2002), co-regulatory molecules exhibit ligand-specific interactions with the MR under controlled conditions in an experimental system. The physiological studies in which aldosterone and cortisol have been shown not to be equivalent in activating the $\mathrm{MR}$ in the absence of $11 \beta-\mathrm{HSD} 2$ might therefore be explained by one of the mechanisms described. This specificity undoubtedly involves interactions with coregulatory molecules, which can have distinct tissue-specific profiles of expression. In addition, the N/C interaction may play a critical role in some situations.

In addition to the implications for the diversity of physiological responses mediated through activation of the MR, we would suggest that the importance of these studies lies in the clear demonstration that the direction of the response is determined by the choice of ligand. This is consistent with other steroid receptors where ligands that are selective modulators of the receptor can be identified. It is clear that the conformation induced by ligands is not equivalent, and there is considerable plasticity in the system such that subtle differences in the conformation induced in the receptor will result in structural differences at the surface of the receptor, which in turn will determine interactions with other factors and will ultimately lead either to productive transcriptional activation or indeed to repression of transcription.

In this discussion, we have not focused on the alternate mechanisms of action for the MR. Classically, we think of the receptor acting through an interaction with a response element in the regulatory region of the target gene. This classic transcriptional or genomic mechanism of action has been the focus of most studies, particularly for the MR. There is now clear evidence that MR signalling may also be mediated through so-called non-genomic or rapid effects of the MR in the cytoplasm where second messenger system signalling pathways are triggered (Fuller \& Young 2005). These mechanisms have been extensively characterised by the work of Grossmann \& Gekle (2012) and also by the group of Harvey (Dooley et al. 2012). As noted previously, tethering or transrepression is an important genomic, but response element independent, method of signalling for the other steroid receptors. This has not been characterised for the MR, but it would seem likely that, as with the other receptors, this is a component of the response. It is important to recognise that many of the above analyses and studies do not presume the mechanism of action, and thus, observations on the N/C interaction or indeed interacting proteins may be relevant, not in the classic pathway, but rather in the cytoplasmic compartment or indeed as part of tethering of other transcription factors.

The relevance of the possibility of modulation at the MR lies in the limitations of the current therapeutic agents. Although RALES (Pitt 2004), EPHESUS (Pitt 2004), EMPHASIS (Zannad et al. 2011) and other clinical trials have shown a clear benefit of the addition of MR antagonist (spironolactone or eplerenone) to standard therapy for cardiac failure and/or ventricular dysfunction in a number of clinical situations, the benefits are limited by the physiology of the antagonism, which is to say by the hyperkalaemia (Juurlink et al. 2004), that may result from blocking the MR in epithelial tissues, particularly the distal nephron and presumably the distal colon. The results above therefore provide support for the concept that a ligand for the MR may be identified, which is selective and/or enriched for antagonism in the cardiovascular system but not in the epithelial sodiumtransporting tissues. Given the role and distribution of the $\mathrm{MR}$ in the CNS, other therapeutic possibilities also remain to be explored.

\section{Declaration of interest}

The authors declare that there is no conflict of interest that could be perceived as prejudicing the impartiality of the review.

\section{Funding}

This work is supported by the National Health and Medical Research Council of Australia through a Research Fellowship (P J F), a Postgraduate Scholarship (J Y) and project grants \#1002575, \#1010034 and \#550903. The work is also supported by a Grant-In-Aid from the National Heart Foundation of Australia. Prince Henry's Institute is supported by the Victorian Government's Operational Infrastructure Support Scheme.

\section{Acknowledgements}

The authors wish to thank Claudette Thiedeman for preparation of this manuscript. 


\section{References}

Arriza JL, Weinberger C, Cerelli G, Glaser TM, Handelin BL, Housman DE \& Evans RM 1987 Cloning of human mineralocorticoid receptor complementary DNA: structural and functional kinship with the glucocorticoid receptor. Science 237 268-275. (doi:10.1126/science. 3037703)

Benhamou B, Garcia T, Lerouge T, Vergezac A, Gofflo D, Bigogne C, Chambon P \& Gronemeyer H 1992 A single amino acid that determines the sensitivity of progesterone receptors to RU486. Science 255 206-209. (doi:10.1126/science.1372753)

Bledsoe RK, Montana VG, Stanley TB, Delves CJ, Apolito CJ, McKee DD, Consler TG, Parks DJ, Stewart EL, Willson TM et al. 2002 Crystal structure of the glucocorticoid receptor ligand binding domain reveals a novel mode of receptor dimerization and coactivator recognition. Cell 110 93-105. (doi:10.1016/S0092-8674(02)00817-6)

Bledsoe RK, Madauss KP, Holt JA, Apolito CJ, Lambert MH, Pearce KH, Stanley TB, Stewart EL, Trump RP, Willson TM et al. 2005 A ligandmediated hydrogen bond network required for the activation of the mineralocorticoid receptor. Journal of Biological Chemistry $\mathbf{2 8 0}$ 31283-31293. (doi:10.1074/jbc.M504098200)

Bulynko YA \& O'Malley BW 2011 Nuclear receptor coactivators: structural and functional biochemistry. Biochemistry 50 313-328. (doi:10.1021/ bi101762x)

Caprio M, Feve B, Claes A, Viengchareun S, Lombes M \& Zennaro MC 2007 Pivotal role of the mineralocorticoid receptor in corticosteroid-induced adipogenesis. FASEB Journal 21 2185-2194. (doi:10.1096/fj.06-7970com)

De Bosscher K, Haegeman G \& Elewaut D 2010 Targeting inflammation using selective glucocorticoid receptor modulators. Current Opinion on Pharmacology 10 497-504. (doi:10.1016/j.coph.2010.04.007)

Dietz JD, Du S, Bolten CW, Payne MA, Xia C, Blinn JR, Funder JW \& Hu X 2008 A number of marketed dihydropyridine calcium channel blockers have mineralocorticoid receptor antagonist activity. Hypertension $\mathbf{5 1}$ 742-748. (doi:10.1161/HYPERTENSIONAHA.107.103580)

Dooley R, Harvey BJ \& Thomas W 2012 Non-genomic actions of aldosterone: from receptors and signals to membrane targets. Molecular and Cellular Endocrinology (In press).

Edwards CR, Stewart PM, Burt D, Brett L, McIntyre MA, Sutanto WS, de Kloet ER \& Monder C 1988 Localisation of 11beta-hydroxysteroid dehydrogenase-tissue specific protector of the mineralocorticoid receptor. Lancet 2 986-989. (doi:10.1016/S0140-6736(88)90742-8)

Estébanez-Perpiñá E, Moore JM, Mar E, Delgado-Rodrigues E, Nguyen P, Baxter JD, Buehrer BM, Webb P, Fletterick RJ \& Guy RK 2005 The molecular mechanisms of coactivator utilization in ligand-dependent transactivation by the androgen receptor. Journal of Biological Chemistry $\mathbf{2 8 0}$ 8060-8068. (doi:10.1074/jbc.M407046200)

Evans RM \& Arriza JL 1989 A molecular framework for the actions of glucocorticoid hormones in the nervous system. Neuron 2 1105-1112. (doi:10.1016/0896-6273(89)90177-3)

Fagart J, Huyet J, Pinon GM, Rochel M, Mayer C \& Rafestin-Oblin M-E 2005 Crystal structure of a mutant mineralocorticoid receptor responsible for hypertension. Nature Structural \& Molecular Biology 12 554-555. (doi:10. 1038/nsmb939)

Fagart J, Hillisch A, Huyet J, Bärfacker L, Fay M, Pleiss U, Pook E, Schäfer S, Rafestin-Oblin ME \& Kolkhof P 2010 A new mode of mineralocorticoid receptor antagonism by a potent and selective nonsteroidal molecule. Journal of Biological Chemistry 285 29932-29940. (doi:10.1074/jbc.M110. 131342)

Farman N \& Rafestin-Oblin M-E 2001 Multiple aspects of mineralocorticoid selectivity. American Journal of Physiology. Renal Physiology 280 F181-F192.

Feldman D, Funder JW \& Edelman IS 1973 Evidence for a new class of corticosterone receptor in the rat kidney. Endocrinology 92 1429-1441. (doi:10.1210/endo-92-5-1429)

Fischer K, Kelly SM, Watt K, Price NC \& McEwan IJ 2010 Conformation of the mineralocorticoid receptor N-terminal domain: evidence for induced and stable structure. Molecular Endocrinology 24 1935-1948. (doi:10.1210/ me.2010-0005)
Fru KN, VandeVoort CA \& Chaffin CL 2006 Mineralocorticoid synthesis during the periovulatory interval in macaques. Biology of Reproduction $\mathbf{7 5}$ 568-574. (doi:10.1095/biolreprod.106.053470)

Fuller PJ \& Verity K 1990 Mineralocorticoid receptor gene expression in the gastro-intestinal tract: distribution and ontogeny. Journal of Steroid Biochemistry 36 263-267. (doi:10.1016/0022-4731(90)90215-E)

Fuller PJ \& Young MJ 2005 Mechanisms of mineralocorticoid action. Hypertension 46 1227-1235. (doi:10.1161/01.HYP.0000193502.77417.17)

Fuller PJ, Lim-Tio SS \& Brennan FE 2000 Specificity in mineralocorticoid versus glucocorticoid action. Kidney International 57 1256-1264. (doi:10. 1046/j.1523-1755.2000.00959.x)

Fuller PJ, Yao Y, Young MJ \& Rogerson FM 2010 Identification and characterisation of ligand-specific co-activators of the mineralocorticoid receptor. 92nd Annual Meeting of the Endocrine Society, San Diego, Abstract June 2010.

Funder JW, Pearce PT, Smith R \& Smith AI 1988 Mineralocorticoid action: target tissue specificity is enzyme, not receptor, mediated. Science $\mathbf{2 4 2}$ 583-585. (doi:10.1126/science.2845584)

Fuse H, Kitagawa H \& Kato S 2000 Characterization of transactivational property and coactivator mediation of rat mineralocorticoid receptor activation function-1 (AF-1). Molecular Endocrinology 14 889-899. (doi:10. $1210 /$ me.14.6.889)

Geerling JC \& Loewy AD 2009 Aldosterone in the brain. American Journal of Physiology. Renal Physiology 297 F559-F576. (doi:10.1152/ajprenal.90399. 2008)

Geller DS, Farhi A, Pinkerton N, Fradley M, Moritz M, Spitzer A, Meinke G, Tsai FT, Sigler PB \& Lifton RP 2000 Activating mineralocorticoid receptor mutation in hypertension exacerbated by pregnancy. Science 289 119-123. (doi:10.1126/science.289.5476.119)

Gomez-Sanchez EP, Venkataraman MT, Thwaites D \& Fort C 1990 ICV infusion of corticosterone antagonizes ICV-aldosterone hypertension. American Journal of Physiology, 258 E649-E653.

Gronemeyer H, Gustafsson JA \& Laudet V 2004 Principles for modulation of the nuclear receptor superfamily. Nature Reviews 3 950-964. (doi:10.1038/nrd1551)

Grossmann C \& Gekle M 2012 Interaction between mineralocorticoid receptor and epidermal growth factor receptor signalling. Molecular and Cellular Endocrinology (In press).

He B, Kemppainen JA, Voegel JJ, Gronemeyer H \& Wilson EM 1999 Activation function 2 in the human androgen receptor ligand binding domain mediates interdomain communication with the $\mathrm{NH}_{2}$-terminal domain. Journal of Biological Chemistry 274 37219-37225. (doi:10.1074/jbc. 274.52.37219)

He B, Kemppainen JA \& Wilson EM 2000 FXXLF and WXXLF sequences mediate the $\mathrm{NH}_{2}$-terminal interaction with the ligand binding domain of the androgen receptor. Journal of Biological Chemistry 275 22986-22994. (doi:10.1074/jbc.M002807200)

Hellal-Levy C, Fagart J, Souque A \& Rafestin-Oblin ME 2000 Mechanistic aspects of mineralocorticoid receptor activation. Kidney International $\mathbf{5 7}$ 1250-1255. (doi:10.1046/j.1523-1755.2000.00958.x)

Hoppmann J, Perwitz N, Meier B, Fasshauer M, Hadaschik D, Lehnert H \& Klein J 2010 The balance between gluco- and mineralo-corticoid action critically determines inflammatory adipocyte responses. Journal of Endocrinology 204 153-164. (doi:10.1677/JOE-09-0292)

Hultman ML, Krasnoperova NV, Li S, Du S, Xia C, Dietz JD, Lala DS, Welsch DJ \& Hu X 2005 The ligand-dependent interaction of mineralocorticoid receptor with coactivator and corepressor peptides suggests multiple activation mechanisms. Molecular Endocrinology 19 1460-1473. (doi:10.1210/me.2004-0537)

Iñiguez-Lluhi JA \& Pearce D 2000 A common motif within the negative regulatory regions of multiple factors inhibits their transcriptional synergy. Molecular and Cellular Biology 20 6040-6050. (doi:10.1128/MCB.20.16. 6040-6050.2000)

Jausons-Loffreda N, Chabret C \& Pons M 1994 Role of the A/B region of the human mineralocorticoid receptor in aldosterone response selectivity. Biochemical and Biophysical Research Communications 205 1610-1616. (doi:10. 1006/bbrc.1994.2851) 
Joëls M, Karst H, DeRijk R \& de Kloet R 2007 The coming out of the brain mineralocorticoid receptor. Trends in Neurosciences 31 1-7. (doi:10.1016/j. tins.2007.10.005)

Juurlink DN, Mamdani MM, Lee DS, Kopp A, Austin PC, Laupacis A \& Redelmeier DA 2004 Rates of hyperkalemia after publication of the randomized aldactone evaluation study. New England Journal of Medicine 351 543-551. (doi:10.1056/NEJMoa040135)

Keightley M-C, Curtis AJ, Chu S \& Fuller PJ 1998 Structural determinants of cortisol resistance in the guinea pig glucocorticoid receptor. Endocrinology 139 2479-2485. (doi:10.1210/en.139.5.2479)

Kino T, Jaffe H, Amin ND, Chakrabarti M, Zheng Y-L, Chrousos GP \& Pant HC 2010 Cyclin-dependent kinase 5 modulates the transcriptional activity of the mineralocorticoid receptor and regulates expression of brain-derived neurotrophic factor. Molecular Endocrinology 24 941-952. (doi:10.1210/me. 2009-0395)

Kitagawa H, Yanagisawa J, Fuse H, Ogawa S, Yogiashi Y, Okuno A, Nagasawa H, Nakajima T, Matsumoto T \& Kato S 2002 Ligand-selective potentiation of rat mineralocorticoid receptor activation function 1 by a CBP-containing histone acetyltransferase complex. Molecular and Cellular Biology 22 3698-3706. (doi:10.1128/MCB.22.11.3698-3706. 2002)

Langley E, Zhou ZX \& Wilson EM 1995 Evidence for an anti-parallel orientation of the ligand-activated human androgen receptor dimer. Journal of Biological Chemistry 270 29983-29990. (doi:10.1074/jbc.270.10. 5251)

Li Y, Suino K, Daugherty J \& Xu HE 2005 Structural and biochemical mechanisms for the specificity of hormone binding and coactivator assembly by mineralocorticoid receptor. Molecular Cell 19 367-380. (doi:10. 1016/j.molcel.2005.06.026)

Lombes M, Kenouch S, Souque A, Farman N \& Rafestin-Oblin ME 1994 The mineralocorticoid receptor discriminates aldosterone from glucocorticoids independently of the 11 beta-hydroxysteroid dehydrogenase. Endocrinology 135 834-840. (doi:10.1210/en.135.3.834)

Luisi BF, Xu WX, Otwinowski Z, Freedman LP, Yamamoto KR \& Sigler PB 1991 Crystallographic analysis of the interaction of the glucocorticoid receptor with DNA. Nature 352 497-505. (doi:10.1038/352497a0)

Mangelsdorf DJ, Thummel C, Beato M, Herrlich P, Schutz G, Umesono K, Blumberg B, Kastner P, Mark M, Chambon P et al. 1995 The nuclear receptor superfamily: the second decade. Cell 83 835-839. (doi:10.1016/ 0092-8674(95)90199-X)

Martinez ED, Pattabiraman N \& Danielsen M 2005 Analysis of the hormonebinding domain of steroid receptors using chimeras generated by homologous recombination. Experimental Cell Research 308 320-333. (doi:10.1016/j.yexcr.2005.03.040)

Massaad C, Lombès M, Aggerbeck M, Rafestin-Oblin M-E \& Barouki R 1997 Cell-specific, promoter-dependent mineralocorticoid agonist activity of spironolactone. Molecular Pharmacology 51 285-292.

Métivier R, Stark A, Flouriot G, Hübner MR, Brand H, Penot G, Manu D, Denger S, Reid G, Kos M et al. 2002 A dynamic structural model for estrogen receptor- $\alpha$ activation by ligands, emphasizing the role of interactions between distant $\mathrm{A}$ and $\mathrm{E}$ domains. Molecular Cell 10 1019-1032. (doi:10.1016/S1097-2765(02)00746-3)

Mihailidou AS \& Funder JW 2005 Nongenomic effects of mineralocorticoid receptor activation in the cardiovascular system. Steroids 70 347-351. (doi:10.1016/j.steroids.2005.02.004)

Miner JN, Chang W, Chapman MS, Finn PD, Hong MH, López FJ, Marschke KB, Rosen J, Schrader W, Turner R et al. 2007 An orally active selective androgen receptor modulator is efficacious on bone, muscle, and sex function with reduced impact on prostate. Endocrinology 148 363-373. (doi:10.1210/en.2006-0793)

Nordeen SK, Bona BJ, Beck CA, Edwards DP, Borror KC \& DeFranco DB 1995 The two faces of a steroid antagonist: when an antagonist isn't. Steroids 60 97-104. (doi:10.1016/0039-128X(94)00001-S)

Odermatt A \& Atanasov AG 2008 Mineralocorticoid receptors: emerging complexity and functional diversity. Steroids 74 163-171. (doi:10.1016/j. steroids.2008.10.010)
Odermatt A, Arnold P \& Frey FJ 2001 The intracellular localization of the mineralocorticoid receptor is regulated by 11 beta-hydroxysteroid dehydrogenase type 2. Journal of Biological Chemistry 276 28484-28492. (doi:10.1074/jbc.M100374200)

Pascual-Le Tallec L, Simone F, Viengchareun S, Meduri G, Thirman MJ \& Lombès M 2003 Protein inhibitor of activated signal transducer and activator of transcription 1 interacts with the $\mathrm{N}$-terminal domain of mineralocorticoid receptor and represses its transcriptional activity: implication of small ubiquitin-related modifier 1 modification. Molecular Endocrinology 17 2529-2542. (doi:10.1210/me.2003-0299)

Pippal JB, Yao Y, Rogerson FM \& Fuller PJ 2009 Structural and functional characterisation of the interdomain interaction in the mineralocorticoid receptor. Molecular Endocrinology 23 1360-1370. (doi:10.1210/me.20090032)

Pippal JB, Cheung CMI, Yao Y-Z, Brennan FE \& Fuller PJ 2011 Characterization of the zebrafish (Danio rerio) mineralocorticoid receptor. Molecular and Cellular Endocrinology 332 58-66. (doi:10.1016/j.mce.2010. 09.014)

Pitt B 2004 Effect of aldosterone blockade in patients with systolic left ventricular dysfunction: implications of the RALES and EPHESUS studies. Molecular and Cellular Endocrinology 217 53-58. (doi:10.1016/j.mce.2003. 10.009)

Qin W, Rudolph AE, Bond BR, Rocha R, Blomme EAG, Goeliner JJ, Funder JW \& McMahon EG 2003 Transgenic model of aldosterone-driven cardiac hypertrophy and heart failure. Circulation Research 93 69-76. (doi:10.1161/01.RES.0000080521.15238.E5)

Quigley CA, Tan JA, He B, Zhou ZX, Mebarki F, Morel Y, Forest MG, Chatelain P, Ritzén EM, French FS et al. 2004 Partial androgen insensitivity with phenotypic variation caused by androgen receptor mutations that disrupt activation function 2 and the $\mathrm{NH}(2)$ - and carboxyl-terminal interaction. Mechanisms of Ageing and Development 125 683-695. (doi:10. 1016/j.mad.2004.08.007)

Rafestin-Oblin ME, Souque A, Bocchi B, Pinon G, Fagart J \& Vandewalle A 2003 The severe form of hypertension caused by the activating S810L mutation in the mineralocorticoid receptor is cortisone related. Endocrinology 144 528-533. (doi:10.1210/en.2002-220708)

Rickard AJ \& Young MJ 2009 Corticosteroid receptors, macrophages and cardiovascular disease. Journal of Molecular Endocrinology 42 449-459. (doi:10.1677/JME-08-0144)

Rickard AJ, Morgan J, Tesch G, Funder JW, Fuller PJ \& Young MJ 2009 Deletion of mineralocorticoid receptors from macrophages protects against DOC/salt-induced cardiac fibrosis and increased blood pressure. Hypertension 54 537-543. (doi:10.1161/HYPERTENSIONAHA.109. 131110)

Robin-Jagerschmidt C, Wurtz J-M, Guillot B, Gofflo D, Benhamou B, Vergezac A, Ossart C, Moras D \& Philibert D 2000 Residues in the ligand binding domain that confer progestin or glucocorticoid specificity and nodulate the receptor transactivation capacity. Molecular Endocrinology 14 1028-1037. (doi:10.1210/me.14.7.1028)

Rogerson FM \& Fuller PJ 2003 Interdomain interactions in the mineralocorticoid receptor. Molecular and Cellular Endocrinology 200 45-55. (doi:10.1016/S0303-7207(02)00413-6)

Rogerson FM, Dimopoulos N, Sluka P, Chu S, Curtis AJ \& Fuller PJ 1999 Structural determinants of aldosterone binding selectivity in the mineralocorticoid receptor. Journal of Biological Chemistry 274 36305-36311. (doi:10.1074/jbc.274.51.36305)

Rogerson FM, Yao YZ, Smith BJ, Dimopoulos N \& Fuller PJ 2003 Determinants of spironolactone binding specificity in the mineralocorticoid receptor. Journal of Molecular Endocrinology 31 573-582. (doi:10.1677/ jme.0.0310573)

Rogerson FM, Yao Y-Z, Smith BJ \& Fuller PJ 2004 Differences in the determinants of eplerenone, spironolactone and aldosterone binding to the mineralocorticoid receptor. Clinical and Experimental Pharmacology \& Physiology 31 704-709. (doi:10.1111/j.1440-1681.2004.04079.x)

Rogerson FM, Yao Y-Z, Elsass RE, Dimopoulos N, Smith BJ \& Fuller PJ 2007 A critical region in the mineralocorticoid receptor for aldosteorne 
binding and activation by cortisol: evidence for a common mechanism governing ligand binding specificity in steroid hormone receptors. Molecular Endocrinology 21 817-828. (doi:10.1210/me.2006-0246)

Rossier MF, Lenglet S, Vetterli L, Python M \& Maturana A 2008 Corticosteroids and redox potential modulate spontaneous contractions in isolated rat ventricular cardiomyocytes. Hypertension 52 721-728. (doi:10. 1161/HYPERTENSIONAHA.108.114223)

Sato A \& Funder JW 1996 High glucose stimulates aldosterone-induced hypertrophy via type 1 mineralocorticoid receptors in neonatal rat cardiomyocytes. Endocrinology 137 4145-4153. (doi:10.1210/en.137.10. 4145)

Savkur RS \& Burris TP 2004 The coactivator LXXLL nuclear receptor recognition motif. Journal of Peptide Research 63 207-212. (doi:10.1111/j. 1399-3011.2004.00126.x)

Schaufele F, Carbonell X, Guerbadot M, Borngraeber S, Chapman MS, Ma AA, Miner JN \& Diamond MI 2005 The structural basis of androgen receptor activation: intramolecular and intermolecular aminocarboxy interactions. PNAS 102 9802-9807. (doi:10.1073/pnas. 0408819102)

Sturm A, Bury N, Dengreville L, Fagart J, Flouriot G, Rafestin-Oblin ME \& Prunet P 2005 11-Deoxycorticosterone is a potent agonist of the rainbow trout (Oncorhynchus mykiss) mineralocorticoid receptor. Endocrinology 146 47-55. (doi:10.1210/en.2004-0128)

Tetel MJ, Giangrande PH, Leonhardt SA, McDonnell DP \& Edwards DP 1999 Hormone-dependent interaction between the amino- and carboxylterminal domains of progesterone receptor in vitro and in vivo. Molecular Endocrinology 13 910-924. (doi:10.1210/me.13.6.910)

Thompson J, Saatcioglu F, Jänne OA \& Palvimo JJ 2001 Disrupted aminoand carboxyl-terminal interactions of the androgen receptor are linked to androgen insensitivity. Molecular Endocrinology 15 923-935. (doi:10.1210/ me.15.6.923)

Trapp T \& Holsboer F 1995 Ligand-induced conformational changes in the mineralocorticoid receptor analysed by protease mapping. Biochemical and Biophysical Research Communications 215 286-291. (doi:10.1006/bbrc.1995. 2464)

Usher MG, Duan SZ, Ivaschenko CY, Frieler RA, Berger S, Schütz G, Lumeng CN \& Mortensen RM 2010 Myeloid mineralocorticoid receptor controls macrophage polarization and cardiovascular hypertrophy and remodeling in mice. Journal of Clinical Investigation 120 3350-3364. (doi:10. 1172/JCI41080)

Viengchareun S, Le Menuet D, Martinerie L, Munier M, Pascual-Le Tallec L \& Lombes M 2007 The mineralocorticoid receptor: insights into its molecular and (patho)physiological biology. Nuclear Receptor Signalling $\mathbf{5}$ e05012.

Vivat V, Gofflo D, Wurtz J-M, Bourguet W, Philibert D \& Gronemeyer H 1997 Sequences in the ligand-binding domains of the human androgen and progesterone receptors which determine their distinct ligand identities. Journal of Molecular Endocrinology 18 147-160. (doi:10.1677/jme. $0.0180147)$

Wilson P, Morgan J, Funder JW, Fuller PJ \& Young MJ 2009 Mediators of mineralocorticoid receptor-induced profibrotic inflammatory responses in the heart. Clinical Science 116 731-739. (doi:10.1042/CS20080247)

Yang J \& Fuller PJ 2012 Interactions of the mineralocorticoid receptor within and without. Molecular and Cellular Endocrinology (In press).

Yang J \& Young MJ 2009 The mineralocorticoid receptor and its coregulators. Journal of Molecular Endocrinology 43 53-64. (doi:10.1677/JME-09-0031)

Yang J, Chang C-Y, Safi R, Morgan J, McDonnell DP, Fuller PJ, Clyne CD \& Young MJ 2011 Identification of ligand-selective peptide antagonists of the mineralocorticoid receptor using phage display. Molecular Endocrinology 25 32-43. (doi:10.1210/me.2010-0193)

Zannad F, McMurray JJ, Krum H, van Veldhuisen DJ, Swedberg K, Shi H, Vincent J, Pocock SJ \& Pitt B (EMPHASIS-HF Study Group) 2011 Eplerenone in patients with systolic heart failure and mild symptoms. New England Journal of Medicine 364 11-21. (doi:10.1056/NEJMoa1009492)

Zhang J, Simisky J, Tsai FT \& Geller DS 2005 A critical role of helix 3-helix 5 interaction in steroid hormone receptor function. PNAS 102 2707-2712. (doi:10.1073/pnas.0409663102)

\section{Received in final form 24 November 2011 Accepted 12 December 2011 Made available online as an Accepted Preprint 12 December 2011}

